\title{
La evaluación discreta de los libros
}

עr Silvio MatToni / Universidad Nacional de Córdoba - CONiCET / silviomattoni@yahoo.com.ar

\section{Resumen}

A partir de algunas reflexiones acerca del problema del valor en la crítica literaria, nos proponemos poner en cuestión los procesos de cuantificación de las publicaciones en diversos ámbitos académicos, aunque no se ingresa en un análisis institucional al respecto. Desde un punto de vista especulativo, y tomando en cuenta ciertas consideraciones de Roland Barthes y de Maurice Blanchot, como ejemplos de críticos que se consideran autoridades en el espacio literario del presente, intentamos entonces relativizar el horizonte de eficacia y de productividad en el que se tiende a enmarcar la actividad de la crítica, la historia y la teoría literarias. Por otro lado, también se plantea el constante retorno de ese lugar común tanto para debates críticos como para las realizaciones de los géneros literarios y su devenir: el libro.

Palabras clave: valor $\cdot$ lectura $\cdot$ géneros literarios

crítica literaria $\cdot$ escritura

\section{Abstract}

From some reflections about the problem of the value in literary criticism, we propose to put in question the processes of quantification of the publications in diverse academic areas, though it's no to make an institutional analysis in the matter. From a speculative point of view, and bearing in mind certain considerations of Roland Barthes and Maurice Blanchot, as critics' examples that authorities consider in the literary space of the present, we try then to relativize the horizon of efficiency and productivity that tends to frame the activity of the literary critics, history and theory.Moreover, also there appears the constant return of this common place both for critical debates and for the accomplishments of the genres and his evolution: the book.

Key words: value $\cdot$ reading $\cdot$ literary genres $\bullet$ literary criticism $•$ writing 
Ya sea que nos situemos en la crítica literaria, la teoría literaria o incluso la historia de la literatura, resulta difícil pensar que lo escrito en esos campos se dirige sólo a otros especialistas. Puede ser un hecho que así ocurra, incluso también puede ser una imposición institucional: sólo otros especialistas en un autor, un género literario, una modalidad teórica, podrían valorar adecuadamente lo que se hizo. Sin embargo, en primer lugar habría que diferenciar el sitio al que se apunta cuando se escribe sobre literatura, cuando se la interpreta o se la estudia, de los espacios concretos de publicación. Sin dudas, el autor de un determinado análisis de un texto literario no se dirige ante todo a cumplir las normas de una publicación, sino en principio y tal vez a delimitar, asir un poco más de cerca su deseo de verdad. Antes de publicar, escribe porque cree haber encontrado algo y considera que eso que halló o que descubrió o que construyó entrecruzando teorías y obras literarias tiene su grado de acierto. Digamos: quien escribe apunta a su hallazgo y a volverlo más concreto que una pura intuición; quien publica entra en una circulación de valores, acata normas, recibe o no una cuota de reconocimiento.

No obstante, la comunicación del crítico con su propio hallazgo imaginario no podría darse sin el paso por la mirada exterior, sin la exposición pública. Así, algo tan concreto y prosaico como un artículo o un libro editado tendrían la función de confirmar una búsqueda que no está destinada más que a seguir buscando. De allí que el público de la crítica sea mucho menos preciso de lo que supondría la revista o la editorial del libro. Como en la literatura, donde el mercado juega un papel tan ambiguo como exterior a su valoración inmanente, en la interpretación y el análisis de novelas, poemas o ensayos no se puede decir que la publicación material garantice un valor. Así como un poeta secreto, que guarda su obra durante décadas o que la muestra en dosis mínimas y para pocos, puede obtener una alta cuota de prestigio, de igual modo el crítico que no comunica todo lo que interpreta, el que retiene una parte íntima de su glosa teórica, puede resultar el más reconocido.

Ahora bien, nada parece medible en este terreno. ¿Acaso el crítico más citado será el más autorizado, el más reconocido? Sólo si pensamos que el recurso a la autoridad tiene algo más que una función retórica y que por lo tanto puede revertirse y tener un efecto de rebote sobre su propia fuente, de tal manera que aquel que cita un nombre de prestigio para autorizarse a decir algo también refuerza la autoridad del nombre que invoca. Pareciera que en ese orden de los nombres nos moviéramos entre fantasmas. Pierre Bourdieu, que tal vez para nosotros posea la autoridad de un espectador de la literatura pero que permanece ajeno a ella, escribió su famoso Homo academicus estudiando el campo universitario sin descuidar su relación con las letras. No hace falta leer su previsible libro lleno de capitales simbólicos y racionalizaciones de conductas y valoraciones, justamente en un ámbito donde todo lo racional se ha vuelto pulsional, para retener la anécdota: eligió el campo de la enseñanza literaria porque allí se veía más al desnudo que lo único en juego dentro del sistema académico era el prestigio, y no se inmiscuía una cuestión de verdad, ilusión que tal vez apareciera en una supuesta ciencia. 
De hecho, en la crítica literaria, tal como en la filosofía no epistemológica ni formalista, la ciencia aparece plenamente en tanto que ideología cientificista. Es sabido que no hay ciencia sin ideología, ni discurso siquiera, pero lo que se impuso en cierto momento, con más intensidad en determinadas metodologías de lectura, fue la ciencia misma como ideología. Con lo cual llegamos a un problema crucial: en la ciencia propiamente dicha, la salvación de la ideología, que no puede desaparecer sino tan sólo desplazarse, se realiza mediante estándares de producción cosa que en la valoración de la crítica no podría aplicarse, ya que la mayor parte de su reconocimiento proviene de su tendencia y de su estilo, de su no-objetividad de principio. La pregunta «¿para quién se escribe?» parece entonces fácilmente engańosa. Se podría responder: para los otros críticos y ensayistas, para las instituciones que pagan el trabajo, para la enseñanza de la literatura, que es también una dudosa premisa de estado, o en un extremo más abierto: para los escritores, los muertos y los que vendrán. Nada impide, en ninguna respuesta bien delimitada, que se trate de ilusiones, puesto que todo conjunto, ese público imaginado, es una fantasía del sujeto que escribe, o incluso, más allá del yo, se trataría de un efecto de aquello que nunca sabe sobre sí. La mirada del otro tiene ese carácter doble, implacable, porque no hay más que ilusión de ser mirado en el momento de alzar la vista. Si la forma menos engañosa de la crítica, la más atenta al hallazgo de quien intenta leer y conocer lo que lee, sería ese alzar la vista del libro para pensar en otro texto, para asociar o relacionar los libros, las formas, las teorías, entonces no habría un público para la huella de tal gesto, tendría que haber alguien, un nombre o un cuerpo, o ambos. Se escribe para alguien.

Si no hay público en el origen, de todos modos ha de existir en los efectos, que a su vez pueden ser un nuevo comienzo. Habría que pensar en la imagen que resulta de las publicaciones que, para el caso del ensayo crítico o la reflexión filosófica, pueden reducirse a dos: revistas y libros. De acuerdo con estándares de otras áreas, la así llamada ciencia normal, un artículo en una revista especializada tendría más validez, puesto que se sometió a un esotérico proceso de evaluación, sin nombres. A alguien le llega un ensayo o una exposición de temas de literatura, una presentación de textos nuevos o recuperados de la historia infinita, sin el prejuicio de la firma. Pero en ese ámbito, ¿no se busca siempre un nombre? El desconcertado árbitro de la revista intenta adivinar quién escribió lo que le enviaron. ¿Lo habrán escrito para él? Además de este dudoso procedimiento, que ocasionalmente puede mejorar un artículo, aunque habría que tenerle la misma fe que a los talleres literarios para perfeccionar una novela o un poema («y lo que nos falta es la fe», decía Hegel para toda la modernidad), la revista garantizaría una recepción específica: otros que estudian algo similar leerán el artículo. Sin embargo, lo cierto es que las revistas no se leen de ese modo y que el fantasma del libro pesa más que docenas de papeles navegando en revistas a la hora de citar. La misma anonimia que presidió su evaluación inicial gravita sobre el artículo de la revista, que físicamente no viaja pero que tampoco virtualmente sale del maremoto informativo de los buscadores. Sin firma en su origen, ¿con qué nombre se buscaría 
su verdad o su ilusión de pensamiento? Por el tema, podrían contestarnos. Pero cualquiera que haya puesto un tema en su pantalla de búsqueda sabrá que inevitablemente perderá su tiempo en una escasez decepcionante o, peor aún, en una abundancia banal. El libro, en cambio, aun el que se editó a una distancia y en un tiempo remoto, trae de nuevo la idea de literatura. En su pequeño libro de artículos minuciosos —o de ensayos delirantes, la supuesta objetividad ya no tiene peso en el pensamiento del libro-, el crítico o el historiador imagina la literatura, quiere explicarla sin separarse de ella, sueña que el tiempo, que barre con todo saber, lo puede salvar de su dedicación al trabajo. Porque el libro, además, no se dirige tanto al espacio de la crítica, a otros especialistas, imaginarios o concretos, sino que apunta a todo el que pueda interesarse. El libro sobre literatura dice que el poema, la novela y el ensayo deben ser hechos por todos, no por uno. Tampoco la literatura a secas, si es que institucionalmente aceptamos que la crítica no es literatura como cualquier otro género, se dirige a una esfera determinada. El mercado discrimina lectores de novelas, bastantes, lectores de ensayos, subdivididos a su vez por zonas de interés, un poco menos, lectores de poesía, casi nulos. La literatura, que se piensa en la lengua, que se habla en el acto de escribir, no se mide por esas cantidades. En la librería del centro comercial, donde casi nada es literatura, siquiera anquilosada, un lector se arrastra por el piso alfombrado para revisar los lomos de libros de poemas y el anaquel estrecho de la crítica literaria. No obstante, su existencia curiosa salva la idea de libro. También el libro de un crítico apunta a los que vendrán, que en efecto llegan, por cientos, cada año, a las aulas en donde habla, donde ensaya. Si es al menos un intelectual, ya que nadie puede saber si es o no un escritor, habrá escrito su habla y luego hablará su libro, todo con el nombre propio, sin más referato que la atención o la distracción de un puñado de jóvenes que aman la literatura.

Por lo tanto, la pregunta que se le hace al crítico — ¿para quién escribe?- esconde su propia imposibilidad de ser respondida. Podría decirse que se escribe para aquellos que lo requieren, por la vía de ese encargo que en otros tiempos era función del editor de revistas solicitar sobre la base de temas o cuestiones o nombres, pero si se trata de libros, e incluso de artículos sobre libros, no puede darse una respuesta meramente empírica. Sería como reducir la literatura a la expectativa o la esperanza vana de un mercado. De allí que lo irresoluble de la pregunta que se le hace a la escritura del crítico, una pregunta por su gratuidad, ya hubiera aparecido en la misma pregunta hecha al escritor: ¿para quién escribe? A la que se le dieron respuestas comprometidas que sólo condenaban la literatura a la futilidad de un mensaje. Si se trata de esclarecer conciencias mostrándoles las contradicciones de la sociedad, los conflictos y las ideologías de un presente, ¿para qué usar novelas o menos aún poemas? En tales casos, se trata de hablar, tomar partido, opinar. Pero el objeto de la literatura es otro. El escritor, tal vez, escribe para el deseo del otro. Es decir que no sabe si hay un «quién» en el acto que lo impulsa. Barthes reivindicó esta ausencia del sujeto consciente en el espacio de la escritura y con ello soslayó de manera tajante la respuesta comprometida con 
un «quién» socialmente determinado. Y en ciertos géneros, los menos absorbidos por la ilusión referencial del lenguaje, el "para quién» se cae por su propio peso, cae en el absurdo. ¿Acaso un poema se dirige a una clase, a un público? Aun en su forma más banal, que diría: «un poema se dirige a los poetas», no deja de ser una respuesta vacía. La aparición del interlocutor de ese aparato lingüístico que convencionalmente llamamos, todavía, "poema» puede demorar, como dijera Osip Mandelstam, "más de lo que tarda la luz de una estrella en alcanzar a otra».

Por supuesto, el ensayo crítico está más cerca del habla, toma posición, es discutible, aunque no sea demostrable. Pero no podría dirigirse sólo al especialista en su objeto, ya que en su escritura dicho objeto es sólo un medio, un pretexto para intervenir en la vida o para que entre los intersticios de los libros se cuele allí un contenido vital. Y para la pasión del crítico literario la literatura es la vida. ¿Cómo se manifiesta este sitio del crítico en su escritura, lo que quiere que sea la literatura? En lo que valora, que es también el valor que quiere para sí. Barthes, procurando distinguir el acto crítico de la postura discursiva del intelectual y de las prácticas eróticas del profesor, afirmó, con la autoridad de su propia resistencia incómoda frente a los estándares de la investigación: «La evaluación precede a la crítica. No es posible poner en crisis sin evaluar. Nuestro valor es la escritura» (Io6). Y precisamente, cuando se pregunta por el destino material de su escrito, el crítico se interroga sobre el valor. Ni el prestigio de una revista ni el nombre propio en letras gruesas sobre una mesa de librería tienen algo que ver con ese valor, aun cuando sean, imaginariamente, vehículos que harían posible la evaluación. El valor, que por definición es inaccesible ya que pertenece a otros (otras lecturas, otros lugares, otros tiempos), se funda en la autoridad. Lo que no define nada, ya que también la autoridad se origina en las valoraciones. Pero más allá de este círculo, la autoridad tiene su correlato objetivo en la experiencia, que en la crítica sólo puede ser experiencia de lectura. Lo que el crítico valora, ama, en lo que lee, será la experiencia, el goce y el placer, que teñirán con su autoridad tácita esa escritura crítica, cuyos objetos de interés serán las pruebas de un deseo que insiste. En última instancia, más allá de las apariciones teóricas y las argumentaciones que procuran convencer, el valor de la crítica estará en aquello que no maneja, una autoridad que le llega de donde no sabe, de lo que busca, y por ende, si su forma es una comunicación, no será tanto un mensaje lo que se transmite, sino en parte un agente de contagio. Lo valorado se contagia, después viene la interpretación, a la que también podemos llamar investigación.

Por otro lado, quizás haya también un espacio de transición entre el intelectual, el profesor, el escribiente y el escritor, porque justamente Barthes despliega ese juego de figuras para situarse en cada uno de esos fantasmas. Detrás de las fantasías de escribir para alguien, nadie sabe quién es cuando escribe, mucho menos qué es. La función viene dada, está en el orden que obliga a hablar, que fuerza a que la escritura no sabida hable, pretenda saber. La investigación sustituye entonces el espacio vacante, la transición o la indeterminación entre los roles sociales. «¿Qué es una “investigación”? Para saberlo, habría que tener alguna idea 
sobre lo que es un "resultado”. ¿Qué se encuentra? ¿Qué se quiere encontrar? ¿Qué falta?» (Barthes:90). La incertidumbre no sólo del resultado, sino de que exista un resultado, refleja la misma inaccesibilidad del quién. ¿Quién falta en la investigación? No el objeto, no lo simplemente hallado, sino el que escribe. Alguien dijo: escribir es investigarse uno mismo. Barthes, voz y nombre de una autoridad que no separaba la literatura del estudio, ni la novela del haiku, ni la autobiografía de la crítica literaria, lo confirma: «La investigación es, entonces, el nombre prudente que, bajo la violencia de determinadas condiciones sociales, le damos al trabajo de escritura: la investigación está de parte de la escritura, es una aventura del significante, un exceso en el intercambio» (9I).

Por supuesto, el que cree estar arriesgando un hallazgo, un resultado — ¿y quién podría escribir el más mínimo ensayo sin esa creencia, sin tener una «idea»?-, no puede saber que nadie espera su oferta. La ausencia del lugar al que se dirige lo que escribimos crea la necesidad de imaginarlo. La revista, el libro, tan diferentes en su modo de circulación y de valoración, son sin embargo de la misma índole: lugares imaginarios para empezar a escribir. La pregunta barthesiana «ipor dónde empezar?» se contesta con la práctica de Barthes: pensando, soñando tal vez, imaginando los lugares en donde lo escrito se verá editado, donde al fin la mano demasiado personal que traza unas grafías anómalas se verá reflejada en letras de molde, todas iguales a sí mismas, allí donde sólo la firma, reducida a nombre identificatorio, puede diferenciar un texto.

Pero obviamente hay un problema en la imposibilidad lógica de pensar bajo conceptos generales lo singular. El nombre mismo, propio pero fantasmal, heredado, ya generaliza una singularidad que sólo existe en lo escrito, en sus vacilaciones y sus afirmaciones, en una búsqueda que no tiene fin, aunque pase por muchos objetos. Así, la pregunta «¿para quién escribimos?» debe pasarse, al menos mentalmente, por pudor o por conveniencia, a la primera persona: ¿para quién escribo? No sólo se singulariza entonces el sujeto de la escritura —algo que la práctica efectiva insiste en mostrar: no se escribe colectivamente-, sino también el interlocutor o el deseo de que haya alguien. En este sentido, el libro tiene un privilegio fundamental por encima de cualquier tipo de revista, y de allí que su valor siga imponiéndose más allá de los intentos de cuantificar una clase de investigación que sólo tiene por objeto, precisamente, libros. La crítica quiere ser tan válida, tan rigurosa, como la literatura. En tanto que evalúa los libros no por sus efectos ni por su representatividad, sino por su escritura, el ensayo -y sus formas subyacentes en la así llamada investigación- aspira a recibir la misma evaluación, y lo que a fin de cuentas habrá de encontrar, sin saberlo, sin ninguna garantía de continuidad, es su autoridad.

Tampoco la autoridad, a su vez, puede atribuirse a un sujeto colectivo - permítase este oxímoron, dadas las afirmaciones precedentes_- La autoridad de un escrito está en su lectura, que lo construye como fuente. Pero se trata de la lectura como singularidad, es decir, como nueva escritura. No habría un rebaño para la voz pastoral del autor, así como no hay un público en la escritura, sino un quién, 
un cualquiera pero singular. La pastoral implicaría que el lugar en que se recibirá lo escrito ya existía antes del acto de escritura. Por lo cual, incluso los libros que se normalizan podrían volverse instituciones, no acontecimientos. La pregunta entonces - ¿para quién se escribe?, o su correlato: ¿quién escribe?- esconde un intento de resistir a la normalización del saber, apostando lo que no se sabe que se tiene; la pregunta escribe antes de saber para quién, aunque su resistencia no provoca escándalo, no incita a la inmolación del nombre. De hecho, aun en la más aceitada evaluación institucional, sigue habiendo nombres. A esa resistencia, que insiste en seguir escribiendo, de nuevo Barthes nos ayuda a nombrarla: cierta flotación, cierta fluctuación. No del todo saberes pero sí matices de lo que circula, no del todo expresión pero sí atención al estilo. Al fin y al cabo, si la literatura a secas ya no se valora por su forma bella, sino por su pertinencia o su precisión, por su resistencia o por su irrepetibilidad, ¿no deberá la crítica, que desenganchó la identificación entre belleza y verdad hasta disolver sus mismas condiciones de posibilidad, imaginarse a su vez precisa, pertinente, desobediente y nueva? Y podría decirse del crítico y su horizonte lo mismo que Blanchot dijera del escritor en general: «en tanto siga siendo una persona real y crea ser esa persona real que escribe, también cree con naturalidad que alberga en él al lector de lo que escribe» (I89). Pero no debería darle crédito a esa imagen: no se sabe nada del lector, no está para nada en lo escrito. Si alguien cree encarnar el juicio de lo que se está escribiendo, advierte Blanchot, salen «esas hermosas frases que no podemos llamar escritas sino tan sólo legibles» (I89). En última instancia, se escribe para el mundo de las cosas, para la realización del libro. Por eso es que tal vez la crítica, el análisis, los comentarios de lectura, encuentren en las revistas no la especialización, la superstición de un valor de verdad, la apariencia de un rigor, sino aquello mismo que la literatura moderna supo concebir en las llamadas revistas literarias, tanteos para el libro.

No podemos sino insistir en el mismo espacio de la incertidumbre: la crítica sobre literatura se dirige al mismo punto que la literatura, a la pregunta y a su aplazamiento infinito. ¿Quién lee? La respuesta no podría reducirse a una impostación del sujeto que escribe ni a sus modos de leer. El crítico, el escritor han leído, pero los autores que amaban están muertos. La persona real que escribe ahora no podría dejar de retroceder ante la afirmación amenazante pero evidente que reza: «Todo autor es un muerto» (Monteleone:I5). ${ }^{1}$ Así parece también que la lectura fuera el reconocimiento de la autoridad, la potencia imaginaria, el fantasma de su nombre. Sin embargo, el crítico no se entrega del todo a una palabra completamente última, habla todavía en la precaria institución de la evaluación literaria, la vanidad y la vacuidad de sus figuraciones pueden no valer nada pero no serán tan sólo mala literatura, porque reiteran el rito de la lectura, sobreactuándolo, confirmando enfáticamente la incierta continuidad del amor a los libros. Blanchot, que es el ejemplo insigne de un estilo de escritor que deslumbra de inteligencia crítica - y que arruinó todas sus novelas porque no podía dejar de leerse, de querer leerse a sí mismo-, concluye, o más bien aplaza toda conclusión, paradójicamente: 
La lectura nace entonces en ese momento en que el «vacío», que durante la génesis de la obra señalaba su inacabamiento, señalaba también la intimidad de su progresión, el impulso de "el ser que proyecta»; la lectura nace en ese momento en que la distancia de la obra respecto de sí cambia de signo y ya no indica su inacabamiento sino su realización, ya no significa que aún no ha sido realizada, sino que nunca hubo de serlo. (I89)

El libro siempre está por venir, de allí la potencia infinita de su inacabamiento: en cualquier instante puede ser extraído de su sueño entre las cosas, de la biblioteca, y empezar de nuevo, realizarse como desplazamiento, como crítica, e incluso como crítica de la crítica. Y si la idea de la poesía, su despliegue y su esperanza de sobrevida, es la prosa (crítica), la idea de la crítica, una crítica que se comenta a sí misma, volverá a ser llamada poesía, que en estos términos románticos vale por literatura. Las revistas en cambio guardan lo ya hecho, pertenecen a la historia, a las instituciones, a la enciclopedia del arte e incluso, si el tiempo lo reclama, a la ciencia. Y sin embargo, quizás la crítica más modesta, la que se dedica rigurosamente a cumplir con normas y a delimitar con claridad sus objetos, sin llegar a la concepción unitaria del libro, por fragmentos, también pueda anunciar las lecturas del tiempo presente, que nunca están dadas, que apenas se enuncian ya se han desplazado.

¿Para quiénes escribir, entonces, sino para los que habrán de buscar en la propia intimidad de lo que más valoran un reflejo o un contraste en sí mismos, un camino perdido? Después vienen los espacios, el trabajo, todo aquello que parece reivindicar cierta utilidad, pero el placer de leer, el goce de escribir, la alegría de pensar no tienen otra realización que su prórroga, su postergación o su deseo de continuidad en el sueño de los otros. Dar una respuesta tajante a la pregunta por la crítica sería quitarle toda posibilidad de identificarse con su deseo, reducirla a una historia de sucesos, cuando más bien lo que la impulsa sería un ritmo de descubrimientos, de asombros.

\section{Notas}

1 Frase taxativa, ironizada, mirada con melancolía, pensada como relación del autor con su obra, pero tamque preside el íncipit de un brillante libro: El fantasma de un nombre de Jorge Monteleone.

bién en la lectura del crítico sobre los poetas del pasado,

\section{Bibliografía}

Barthes, Roland (1974). ¿Por dónde empezar? Barcelona: Tusquets.

Blanchot, Maurice (1955). El espacio literario. Buenos Aires: Paidós, 1969.

Monteleone, Jorge (2016). El fantasma de un nombre. Poesía, imaginario, vida. Rosario: Nube

Negra. 